\title{
Anatomia do monstro: o vitupério de Francisco José Freire ao poema tragicômico
}

Rodrigo Gomes de Oliveira Pinto ${ }^{a}$

\section{Resumo}

Francisco José Freire (1719-1773), conhecido como Cândido Lusitano, no tratado Arte poetica, ou Regras da Verdadeira Poesia em geral, e de todas as suas especies principaes, tratadas com juizo critico (ed. 1748; $2^{a}$ ed. 1759), censura a tragicomédia como gênero de poema misto, vicioso, nem trágico nem cômico, sem proporção e sem unidade, e condena como má poesia Il Pastor Fido, tragicomédia pastoral de Giovanni Battista Guarini (1538-1612), cuja edição príncipe data de 1590. Essa censura do gênero e do afamado poema italiano funda-se na metáfora do monstrum, apresentada nos passos iniciais (vv. 1431) da Epistula ad Pisones, a Arte Poética de Horácio (séc. I a.C.). Esta obra fornece a Francisco José Freire os critérios de julgamento do fazer poético no século XVIII lusitano.

Palavras-chave: Horácio; Francisco José Freire; Giovanni Battista Guarini; tragicomédia; monstrum.

Recebido em: 12/08/2018 Aceito em: 12/11/2018

${ }^{a}$ Colégio Santa Cruz (SP). Doutor em Letras (Literatura Portuguesa) pela Universidade de São Paulo (USP). E-mail: rodrigopinto75@yahoo.com.br 
La idea de una casa hecha para que la gente se pierda es tal vez más rara que la de un hombre con cabeza de toro, pero las dos se ayudan y la imagen del laberinto conviene a la imagen del minotauro. Queda bien que en el centro de una casa monstruosa haya un habitante monstruoso.

Jorge Luis Borges. El libro de los seres imaginarios.

A Arte poetica, ou Regras da Verdadeira Poesia em geral, e de todas as suas especies principaes, tratadas com juizo critico é um tratado que se publicou em dois tomos, em duas edições, nos anos de 1748 e 1759 . O autor, o padre oratoriano lisboeta Francisco José Freire (1719-1773), que se fez conhecido na Arcádia Portuguesa sob o pseudônimo de Cândido Lusitano, arrola, nesse tratado, um conjunto de preceitos que intenta codificar e instruir o fazer poético nos mais variados gêneros. São eles: a tragédia, a comédia, a mímica, a tragicomédia, o poema épico, a écloga, a sátira, a lírica e suas várias espécies, a elegia, o epigrama, a silva, o epitáfio, o emblema e, por fim, a empresa.

Os capítulos XXVIII e XXIX da obra abordam, em particular, a tragicomédia e são denominados, conforme a segunda edição de 1759, respectivamente, Da Tragicomedia: mostrase como he Poesia monstruosa e Juizo sobre a Tragicomedia de Guarini intitulada Il Pastor Fido". Como os títulos dão a saber, o tratadista dedica-se num capítulo ao gênero e noutro ao seu exemplum mais afamado, Il Pastor Fido, tragicomédia pastoral do poeta italiano seiscentista Giovanni Battista Guarini (15381612), impressa pela primeira vez, em Veneza, em 1590. Do gênero, no capítulo XXVIII, Francisco José Freire afirma:

O certo he, que a Tragicomedia he hum monstro na Poesia taõ enorme, e contrafeito, que pódem os Centauros, e as Chimeras parecer huns partos perfeitos da natureza. He hum composto poetico, que formáraõ alguns Authores para desprezo da Poesia, ordenado todo de cousas entre si discordes, inimigas, e incompativeis. (FREIRE, 1759, t. II, p. 150)

No domínio da retórica, o juízo é demonstrativo e opera-se amparado na vividez da metáfora do monstro, por meio da qual é condensado o vitupério de Francisco José Freire à tragicomédia. Trata-se de juízo segundo o qual a tragicomédia é avaliada como gênero de obra resultante da ignorância dos saberes da arte da poesia, resultante da inépcia 
técnica do poeta cujo poema tragicômico é, por ignorância e por inépcia, mal composto. Insista-se, portanto, que, nesses termos, a tragicomédia, entendida como contrafação insciente dos preceitos da arte, afirma-se como gênero que perverte as doutrinas de invenção poética afiançadas por Francisco José Freire, afirma-se, enfim, como monstruosidade à qual a poesia é condenada por artífice incapaz de fazer o que pode a arte, a saber, aperfeiçoar artisticamente a natureza. Na desrazão, o artífice - o poeta - está sujeito apenas a imperfeiçoá-la e a compor monstro sem igual, cuja anomalia, de modo hiperbólico, é tamanha que faz Centauros e Quimeras parecerem bem formados.

Interessa a Francisco José Freire, mediante a metáfora do monstro, pôr em causa a legitimidade da tragicomédia e vituperar a obra de Giovanni Battista Guarini, de modo tanto a reafirmar a ortodoxia de um costume poético que, desde a Itália do século XVI, pela pena de autores como Giason Denores (ca. 1530-1590), desterra a prática desse gênero, quanto a destituir Il Pastor Fido do papel de exemplum privilegiado. Ora, o tratadista entende que, como exemplum no gênero tragicômico, Il Pastor Fido fornece - ainda que não devesse fazê-lo - razão de semelhança a qualquer poeta não só propenso a imitá-lo senão também ambicioso de emulá-lo. A demonstração da monstruosidade da tragicomédia e a negação da auctoritas de Giovanni Battista Guarini no gênero miram, pois, obstar, pelo embaraço, a imitação e a emulação do poema e, mirando-o, fazem-se pela explicitação da desarmonia do todo poético tragicômico e da desproporção das partes que fazem esse todo; afinal, a tragicomédia, para Francisco José Freire, contravém com os protocolos da boa poesia, porque é composição que se faz de tragédia e de comédia, porque é gênero de feição mista, e é repugnante porque misto. Observe-se:

Já examinámos as qualidades da Tragedia, e da Comedia, e differindo estas entre si, em cinco cousas, como he a materia, as pessoas, a dicção, os affectos, e o fim [...]. Veja-se como estas differenças entre si contrarias, e incompativeis se poderaõ unir para formar hum sujeito poetico? Na Tragedia quasi tudo saõ choros, e lamentos, na Comedia tudo alegrias, e graciosidades, e eu naõ sey como se possaõ unir estas contrariedades. (FREIRE, 1759, t. II, p. 150) 
Em razão disso, assevera o tratadista lusitano:

Naõ posso penetrar como de dous contrarios, e de dous extremos venha a compôrse hum mixto perfeito, nem darse hum meyo perfeito, sendo participante de contrariedade, e extremidade de cousas, v. g. da audacia, e do temor naõ póde resultar a fortaleza; porque naõ he possível, que de dous vicios nasça a virtude; e ainda que se aponte algum exemplo v. g. que de dous animaes diversos nasce hum terceiro de outra especie, responde-se, que este exemplo naõ serve para o caso; porque entre a Tragedia, e a Comedia naõ ha simpathia, nem analogia alguma, para que a arte possa unir comsigo hum terceiro parto poetico; e quando se conceda este absurdo, ficará a Tragicomedia sendo hum monstro da arte; porque he fórma contra as regras, que nella se prescreveraõ; do mesmo modo, que os monstros da natureza saõ aquelles, que se affastaõ da geraçaõ natural, e da ordem, que ella mesma lhe deu. (FREIRE, 1759, t. II, p. 150)

Na lição de Francisco José Freire, a desproporção do gênero tragicômico é verossimilmente enunciada, porque é prescrita por meio de analogia de proporção que vincula natureza e arte. Esse vínculo, por ordem de semelhança, estabelece equivalências que permitem o trânsito de categorias analíticas de um membro a outro da proporção, de maneira que o vitupério da Arte poetica de Francisco José Freire penda da natureza, ou, talvez em termos mais precisos, dos discursos que histórica e socialmente a enformam e que, por conseguinte, instauram leis que o monstro, como anomalia, prodígio ou raridade, por natureza - ou contra naturam - perverte, transgride. Trata-se, isso deve ser evidente, do que se considera natural e do que se considera antinatural, do que se enuncia como natureza e como natureza dos seres.

Soa bastante apropriado à compreensão da analogia de proporção, apresentada por Francisco José Freire, o adágio de São Tomás de Aquino (ca. 1225-1274) segundo o qual a arte imita a natureza operando como ela: "ars imitatur naturam in sua operatione" (AQUINO, 2002, p. 867). Tal como afirma Adma Fadul Muhana, trata-se de compreender que não é o caso de o artífice fazer o que faz a natureza ou de se propor à cópia servil das coisas naturais, tomadas como modelo; é o caso de este artífice - poeta ou pintor - fazer como faz a natureza e de se fiar em suas leis, em seus princípios, em suas proporções, para produzir uma obra, de arte, de artifício, que se assemelhe, como verossímil, à verdade da natureza, porque 
seja composta à maneira das coisas naturais (MUHANA, 1997, p. 44). Conforme Francisco José Freire (1759, t. II, p. 151), o monstro despreza essas leis, esses princípios, essas proporções, na medida em que "de dous animaes diversos [não] nasce hum terceiro de outra especie", a tragicomédia despreza as regras da arte da poesia, já que entre a tragédia e a comédia, gêneros de que pendem o misto tragicômico para o autor, só pode haver inimizade, incompatibilidade, contrariedade, discordância e antipatia, nunca a conjugação de que resulte composição feita de unidade e de harmonia.

Deve-se aventar, ademais, que não há monstruosidade se não há sistema doutrinário que a preveja, que institua parâmetros teóricos de conformação dos desvios e de observação das analogias para dedução das anomalias. Nesse sentido, a monstruosidade entende-se e reitera-se como mistura de formas. É isso o que ensina o curso sobre os anormais pronunciado por Michel Foucault, no Collège de France, entre janeiro e março de 1975. Mostra Foucault (2011, p. 54), o monstrum é misto, segundo "uma história natural essencialmente centrada na distinção absoluta e insuperável das espécies, gêneros, reinos etc." Nessa matriz que se sabe aristotélica, portanto, o monstrum é misto de reinos, o animal e o humano, como o Centauro, de cabeça, torso e braços de homem, garupa e pernas de cavalo; misto de espécies, como a Quimera, de cabeça de leão, corpo de cabra e cauda de dragão; misto de indivíduos, como Cérbero; misto de sexos, como o Hermafrodita, que em si reúne o masculino e o feminino (SANTOS, 2002, p. 195; FOUCAULT, 2011, p. 54).

A fauna monstruosa é muitíssimo vasta no bestiário quase borgeano que inclui Esfinges, Harpias, Górgonas, Sereias, Minotauros, Tritões, Hidras, Cilas, Sátiros e tantos outros espécimes híbridos. A hibridez, nesta zoologia teratológica, segundo Michel Foucault, é transgressiva, assim como é transgressivo o misto tragicômico, para Francisco José Freire, porque a tragicomédia é assim inscrita na arte da poesia como bizarria que infringe traços distintivos das convenções de gênero que são, para o autor lusitano, por assim dizer, incontornáveis.

Instituem-se assim, pode-se aventar, os contornos da doxa em que está assentado o juízo de vitupério. Nesse esforço de deslegitimação do gênero e de menoscabo da obra de Giovanni 
Battista Guarini, a Arte poetica de Francisco José Freire trabalha com operações autorizadas e regradas, isto é, opera topos de censura pendente da Epistula ad Pisones, de Horácio (séc. I a.C.). A tragicomédia, portanto, enforma-se, como gênero misto, ao modo do monstrum enunciado nos versos horacianos, em adequação ao aparato demonstrativo do prólogo da epístola:

\author{
Humano capiti cervicem pictor equinam \\ Jungere si velit, \& varias inducere plumas, \\ Undique collatis membris, ut turpiter atrum \\ Desinat in piscem mulier formosa supernè, \\ Spectatum admissi, risum teneatis amici? \\ Credite Pisones, isti tabulae fore librum \\ Persimilem, cujus, velut aegri somnia, vanæ \\ Fingentur species, ut nec pes nec caput uni \\ Reddatur formae. Pictoribus, atque Poëtis \\ Quidlibet audendi semper fuit æqua potestas. \\ Scimus, E hanc veniam petimusque, damusque vicissim: \\ Sed non ut placidis coëant immitia, non ut \\ Serpentes avibus geminentur, tigribus agni. \\ (HORÁCIO, 1758, p. 2-9)
}

Na tradução de Francisco José Freire, esses versos, que vertem os hexâmetros latinos como hendecassílabos soltos e graves, segundo a praxe do tempo, assim se leem:

Se hum Pintor a cabeça humana unisse
Pescoço de cavallo, e de diversas
Penas vestisse o corpo organizado
De membros de animaes de toda a especie,
De sorte que mulher de bello aspecto
Em torpe, e negro peixe rematasse
Vós chamados a ver esta pintura,
O riso soffrerieis? Pois comvosco

Assentay, ò Pisões, que a hum quadro destes

Será muy semelhante aquelle livro

No qual idéas vãs se representem

(Quaes os sonhos do enfermo) de tal modo,

Que nem pés, nem cabeça a huma só fórma

Convenha. De fingir ampla licença

Ao Poeta, e Pintor sempre foy dada:

Assim he; e entre nós tal liberdade

Pedimos mutuamente, e concedemos;

Mas naõ há de ser tanta, que se ajunte

Agreste com suave, e queira unirse

Ave a serpente, cordeirinho a tigre.

(HORÁCIO, 1758, p. 2-9) 
Esses versos abrem a Arte Poetica de Q. Horacio Flacco na tradução ao português. Tal como evidencia o passo citado, Horácio diz conceder-se ao poeta - e ao pintor semelhantemente - "licença" (veniam) para fingir, "para forjar alguma parte extravagante", como propõe Marcos Martinho dos Santos. Porém, o preceptista latino adverte aos Pisões que não se forjem "idéas vãs" (vanae fingentur species) tais quais "este quadro" (isti tabulae) monstruoso, tais quais "sonhos do enfermo" (aegri somnia), em que a extravagante parte se justapõe "de modo incoerente às mais partes da obra" (SANTOS, 2002, p. 195). Nas glosas que marginalmente acompanham a tradução portuguesa de Horácio, Francisco José Freire afirma que essas vanae species são vanae imagines, "imagens vagas; que não são terminadas; que não têm modelo, ou archetypo em a natureza, que não rematão em objecto algum existente" (HORÁCIO, 1758, p. 4).

Deve-se depreender do excerto, à luz da autoridade do tratado De Architectura de Vitrúvio (séc. I a.C.), censura aos pintores "de grutesco, em que a fantasia depravada pinta figuras humanas rematando em folhagens, serpentes em troncos, e outras semelhantes extravagancias" (HORÁCIO, 1758, p. 38; SANTOS, 2002, p. 195), pintores que, em assim fazendo, "fogem de pintar aquellas verdades regulares, e idéas verosimeis, para seguirem fantasias monstruosas" (ou, assim também, porque "pessimamente aconselhados pela sua estragada imaginativa") (HORÁCIO, 1758, p. 8). No mais, expõe-se, nas glosas de Francisco José Freire, reprimenda aos poetas de mesma monta, visto que, para o tratadista, poetas e pintores, uma vez que sejam artífices de artes imitativas, deveriam imitar a natureza em suas razões "para utilidade, e para deleite dos homens" (HORÁCIO, 1758, p. 25). Ora, como ensina o adágio de São Tomás de Aquino, a imitação feita a propósito nem viola as premissas da natureza que bem define e circunscreve os seres, nem desarranja a taxonomia que convencionalmente os designa e os classifica. Porém, para Francisco José Freire, pintores e poetas dignos de censura, em vez disso, "em lugar de pintarem o que he", ao modo do historiador aristotélico, "ou verosimilmente póde ser", ao modo do aristotélico poeta, "passaõ a abusar da sua arte, occupandose em pinturas incompatíveis, que destroem ou a verdade, ou a verosemelhança" (HORÁCIO, 1758, p. 2). 
De acordo com essas lições, em qualquer que seja a composição, pictórica ou poética, por mais extravagantes que se mostrem suas partes, e ao fim são lícitas as extravagâncias se operadas de modo artístico e racional (SANTOS, 2002, p. 195), não convém obra cujo todo, por motivo dessas partes, seja incongruente e inverossímil, obra "que naõ constar de partes entre si próprias, accommodadas, e convenientes, isto he, que naõ observar simplicidade, e unidade no assumpto, na disposiçaõ, no ornato, e no estylo" (HORÁCIO, 1758, p. 2). A metáfora do monstrum, nesse sentido, é assumida como evidentia persuasiva de "quanto he desprezo a falta desta simplicidade, e unidade" (HORÁCIO, 1758, p. 2), "desprezo da Poesia", nos termos da Arte Poetica, ou Regras da Verdadeira Poesia em geral.

Acrescente-se que, segundo os preceitos poéticos aduzidos, os que se sabem afiançados por Francisco José Freire, há obras que compartilham essa monstruosidade, as quais o leitor deve entender como "fiéis cópias" do quadro que figura o monstrum, obras que surgem como exemplos apensos à tradução de Horácio, exemplos a não imitar, a não emular. São elas: Filis e Demofonte, de Antônio da Fonseca Soares (1631-1682), conhecido como Frei Antônio das Chagas, Viriato Trágico, de Brás Garcia Mascarenhas (1596-1656), estampado postumamente, em 1699, Fênix da Lusitânia, publicado em 1649, e Insulana, em 1635, ambos de Manuel Tomás (1585-1665). São todos poemas portugueses aos quais Francisco José Freire apõe um et cetera de valor demonstrativo que parece, à guisa de censura, superlativar o alcance de prática de escrita que a doutrina entende desmedida. No mais, são obras compostas no século XVII cujos títulos, hoje, ainda que soe insciente a generalização, nada significam. E talvez nada signifiquem porque tenham sido naturalizadas as categorias de análise de eruditos setecentistas como Francisco José Freire, e assim sejam esses poemas ou condenados à ilegibilidade, como exemplos de imperícia poética e de má poesia, ou classificados como poemas barrocos, desde fins do século XIX, mediante a taxonomia de Heinrich Wölfflin.

As glosas de Francisco José Freire também referem poema mais antigo e afamado composto por Ludovico Ariosto (1474-1533), o Orlando Furioso, cuja primeira versão data de 1516. O lusitano negativamente o ajuíza não sem afirmar que, na Itália, Horácio, se o pudesse, “acharia iguaes, 
ou mayores monstruosidades" (HORÁCIO, 1758, p. 3) do que aquelas encontradas em terras ibéricas. O poema de Ariosto é vilipendiado em termos bastantemente semelhantes por um contemporâneo de Freire, Francisco de Pina de Sá e de Mello (1695-1773). Ariosto é, para Francisco de Pina e Mello, como amiúde referido, poeta de "muita extravagancia" (HORÁCIO, 1758, p. 3). Assim é qualificado o autor do Orlando Furioso, pois, no "Prolegomeno para a boa intelligencia, conhecimento do poema. Primeira parte", que prefacia o seu Triumpho da Religiaõ. Poema Epico-Polemico, Francisco de Pina e Mello bane o "incrivel" do gênero épico e afirma que produz o "ridiculo", e não o "admiravel", o poeta que busca o "extraordinario", mas não se atém aos "limites da probabilidade" (MELLO, 1756, p. XVIII).

Francisco de Pina e Mello, consoante esses pressupostos, toma o Orlando Furioso como exemplo de poema que excede o controle da verossimilhança e se faz monstruoso:

O Poema de Ariosto está fundado nestes delirios poeticos. O Hippogripho, ou Cavallo de Rugero: os gigantes, e os monstros. $\mathrm{O}$ anel de Angelica, que a fazia invisivel: os combates de Marfisa Bradamante e Oly[m]pia: as visoens, os encantamentos, e outros successos deste caracter, saõ como os sonhos de hum enfermo, aonde naõ ha reprezentaçaõ que naõ seja monstruosidade. (MELLO, 1756, p. XVIII).

Isso, muito brevemente, significa: assim como os aegri somnia ("os sonhos de hum enfermo"), os "delirios poeticos"; assim como o pintor de bizarrias, Ariosto; assim como a pintura do monstro, o poema Orlando Furioso. No discurso de vitupério, Francisco de Pina e Mello, como o conterrâneo, assenta a razão de semelhança - isso é evidente - na autoridade de Horácio, de quem pendem os critérios de julgamento de boa ou má invenção poética.

Itere-se que, embora Quintiliano (séc. I d. C.), ao preceituar a ornamentação do discurso, refira os versos iniciais da Epistula ad Pisones como ilustração de vício elocutivo próprio de quem faz a mescla de palavras sublimes e humildes (sublimia humilibus), arcaicas e novas (uetera nouis), poéticas e vulgares (poetica uulgaribus) (Quint. VIII, 3, 61), é opinião corrente entre os comentadores de Horácio, tal como discute Marcos Martinho dos Santos, que esses versos da epístola miram, sobretudo, a unidade da matéria poética. É essa unidade, como se observou, de acordo com o preceptista latino, que se 
vê em risco se a variação na obra é prodigiosa (SANTOS, 2002, p. 202), pois que, embora a variação seja prescrita para evitar o tédio da invariação, pode-se solapar a unidade da obra por incongruência em casos tomados por excessivos. Francisco José Freire contesta aqueles que veem nesses versos lição sobre a dispositio - ato pragmático de ordenação das partes do poema, no vocabulário da retórica antiga -, escrevendo assim:

Se o Poeta [Horácio] tratasse aqui da disposiçaõ monstruosa, faria consistir a monstruosidade em ter a figura, v. g. a cabeça no lugar dos pés, e estes no lugar superior, para deste modo mostrar huma disposiçaõ contraria à natureza. Porém o que Horacio dá a entender claramente he, que só falla da invençaõ monstruosa em que os pés, e a cabeça naõ se proporcionaõ à fórma do corpo todo. (HORÁCIO, 1758, p. 6)

Nesse sentido, para o tratadista português, em conformidade com a figura que pinta Horácio, assim como o Orlando Furioso em particular, a tragicomédia afirma-se gênero de poema trabalhado por poeta de "fantasia depravada", que prefere, nos termos de Vitrúvio, segundo a síntese teórica construída por Marcos Martinho dos Santos, a "razão falsa" e pretere a "razão da verdade" (SANTOS, 2002, p. 196), ou, como supõem Francisco José Freire e também Francisco de Pina de Sá e de Mello, seguindo a epístola, poeta que compõe livro assemelhado a "sonhos de enfermo". Sabe-se, desses "aegri somnia", Freire escreve serem os sonhos "depravados, varios, extravagantes", e mais disparatados ainda os do "enfermo", porque assim os fazem os "humores perturbados" (HORÁCIO, 1758, p. 6), segundo os usos da medicina de costume hipocrático no diagnóstico da melancolia.

A depravação, a prodigiosa variedade e a extravagância desses "aegri somnia", já se viu, têm como equivalente a vanidade das ideias do livro do mau poeta, ou das "species", conforme se lê na lição em latim. Como ensina Marcos Martinho dos Santos, Horácio emprega esse substantivo em referência à "visão espetacular", tal o delírio do enfermo, "que não é produzida por nenhum ser verdadeiro". Assim, por exemplo, na horaciana "Sátira II 3", é figurado o maníaco, "furiosus" como Orlando, que "concebe espectros alheios à verdade" (species alias ueris) ou, como glosa o tradutor Francisco José Freire, "cousas que naõ se achaõ na natureza, e só se daõ na cabeça dos enfermos, dos loucos, e dos máos Poetas" (HORÁCIO, 1758, p. 6; SANTOS, 2002, p. 210). 
Dessas "idéas vãs" de "fantasia depravada" deve-se afastar o bom poeta, o letrado principiante. Faz reverberá-las a Arte poetica, ou Regras da Verdadeira Poesia em geral, e de todas as suas especies principaes, tratadas com juizo critico. Neste tratado, a explicação do que seja a fantasia segue os seguintes passos:

Todo o objeto, que se representa aos olhos, aos ouvidos e aos outros sentidos, lança hum compendio, huma imagem, huma similhança de si mesmo, a qual sendo recebida pelos sentidos, passa pelos nervos, e orgãos corpóreos, até que chega a imprimirse em o nosso cérebro. A potencia, ou faculdade da alma, que aprehende, e conhece, estes objectos sensiveis, ou para melhor dizer, as suas imagens, he a fantasia, ou imaginativa, a qual porque está (segundo o nosso modo de entender) na parte inferior da alma, lhe poderemos chamar aprehensiva inferior. Tem a nossa alma outra aprehensiva das cousas, a que podemos dar o nome de superior; porque está collocada na parte superior, e racional da alma, e commummente lhe chamamos entendimento. (FREIRE, 1759, t. I, p. 85-86)

Sabe-se, é definição que se fundamenta em Aristóteles. Francisco José Freire a anuncia à luz do tratado Della perfetta poesia italiana, de Ludovico Antônio Muratori (1672-1750), cuja primeira impressão ocorreu em Modena, na Itália, em 1706. Freire, de fato, verteu-o do italiano ao português (MURATORI, 1706, p. 153). A doutrinação da fantasia, assim proposta, pressupõe a teorização aristotélica no terceiro capítulo do De anima (ARISTÓTELES, An III, 3427 a 17-428 b 30). Este, de início, é capítulo das negativas que, como bem entende Maria Cecília Gomes dos Reis na versão da obra em língua portuguesa, integra estratégia aristotélica de comprovação

1 Neste trabalho, ao operar a transliteração do léxico da língua grega, optei por não acentuar as palavras transliteradas, apenas por distinguir as vogais breves e longas

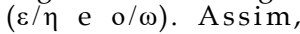
as longas “ $\eta$ " e " $\omega$ " transliteram-se como

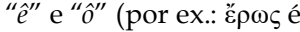
erôs, ao passo que ท̆ $\rho \omega$ é hêrôs). Logo, o "ê" não indica acentuação em grego; indica que a letra em grego é um " $\eta$ " e não " $\varepsilon$ ". Nisso, diga-se, o que proponho não dista do que faz Maria Cecília Gomes dos Reis na edição do $D e$ anima que cito. não só de que noêsis ${ }^{1}$ (intelecção) e phronêsis (entendimento) não se circunscrevem à a aisthêsis (percepção), mas também de que a phantasia se vincula à aisthêsis e não à construção da doxa (opinião) (ARISTÓTELES, 2012, p. 285).

Mirando essa tese, Aristóteles afirma: phantasia não é aisthêsis, nem é dianoia (raciocínio), embora aristotelicamente não haja phantasia sem aisthêsis (ARISTÓTELES, An. III, 3427 a 17 ss.). Não é hypolêpsis (suposição) nem noêsis, porque é pathos (afecção) submisso à vontade humana, distinta da hypolêpsis, insubmissa, da qual pendem emoções que ela, a phantasia, como fantasiada, não suscita (ARISTÓTELES, An. III, 3427 b 16 ss.). É aquilo mediante o que se faz o phantasma (aparição). Não 
é, porém, dynamis (potência) ou hexis (disposição) tais quais aisthêsis, doxa, noêsis e epistêmê (ciência) (ARISTÓTELES, An. III, 3427 b 27 ss.). Não é aisthêsis, (i) porque subsiste nos sonhos, durante o sono, enquanto não atuam os sentidos, (ii) porque não subsiste em todos os animais, embora um dos sentidos, em potência ou em atividade, neles sempre se encontre, (iii) porque pode ser falsa, ao passo que os sentidos jamais o são, se discernem com acuidade, (iv) porque podem subsistir as imagens mentais, mesmo quando os olhos estão fechados (ARISTÓTELES, An. III, 3428 a 5 ss.). Tampouco é noêsis ou epistêmê, porque pode ser falsa, ao passo que estas disposições são sempre verdadeiras. Mesmo admitindo o falso, também não é doxa, porque, conforme Aristóteles, opinar supõe convicção e persuasão, pendentes da razão que falta às feras capazes de fantasiar. E sequer decorre da combinação de doxa e aisthêsis, como afirma Platão (PLATÃO, Soph. 264 a 4-6 ss.), porque é possível que sejam feitas suposições verdadeiras concomitantes com imagens falsas, afinal, consoante o exemplo aristotélico, é possível verdadeiramente crer que o sol seja maior que a terra habitada, ainda que o sentido da visão mostre diminuto o astro (ARISTÓTELES, An. III, 3427 b 16).

Mas a phantasia, Aristóteles afirma após acumular essas negativas todas, "aparenta ser" certa kinêsis, ou seja, certa moção anímica decorrente da energeia (atividade) da aisthêsis, à qual a kinêsis é necessariamente semelhante, e a partir da qual, para os seres humanos e para a maioria das feras, aparecem as já referidas imagens mentais. Essas imagens, sabe-se, na lição aristotélica, são phantasmata ou aparições (ARISTÓTELES, An. III, 3428 b 10-17) e podem ser, como se pôde notar, falsas ou verdadeiras.

Seguindo bastantemente de perto os passos de Ludovico Muratori, de fato vertendo-o à língua portuguesa, Francisco José Freire esmiúça a doutrina: à fantasia, tal como definida, cabe a apreensão das imagens das coisas sensíveis, não a averiguação de sua verdade ou falsidade, ofício da potência que lhe é superior, a porção racional da alma, o entendimento. Digase: entendimento, em Freire, traduz o que Ludovico Antônio Muratori nomeia como intelletto ou giudizio, o que Aristóteles define como phronêsis. Consoante esse conjunto de preceitos, não se confundem, ademais, fantasia e entendimento, e é do comércio entre essas potências anímicas que, de três maneiras, 
as imagens se formam na alma. Ora forma-as (i) o entendimento, por si só, ao abstrair imagem universal de imagens particulares apreendidas pela fantasia. São essas imagens consideradas intelectuais ou engenhosas. Ora formam-nas (ii) a fantasia e o entendimento conjuntamente: este regula as operações daquela, de modo que, do "imperio do entendimento" (FREIRE, 1759, t. I, p. 87), decorram ou imagens de objetos percebidos pelos sentidos ou novas imagens que delas pendam. São essas imagens próprias do poeta. Ora forma-as, por fim, (iii) tão só a fantasia, quando a alma por ela é dominada, alheia aos juízos do entendimento. São essas imagens comuns aos sonhos, às febres, à melancolia. Entende Aristóteles que os homens que têm o intelecto obscurecido pela doença ou pelo sono, e as bestas, que não o têm, muito embora sejam todos dotados dos sentidos, agem de acordo com a fantasia e, por ela, são conduzidos (ARISTÓTELES, An. III, 3428 a 5; 428 b 30). Essa ação sem guias da fantasia, para um leitor aristotélico como Ludovico Antônio Muratori, é, sobretudo, um indefensável desgoverno da razão, cujas razões residem na ineficácia de ofício da fantasia para a distinção de coisas "Vieri o Falsi, Probabili o Improbabili, moralmente Buoni o Cattivi" (Verdadeiras ou Falsas, Prováveis ou Improváveis, moralmente Boas ou Más).

Francisco José Freire, sempre de acordo com Ludovico Antônio Muratori, preceitua que a fantasia poética, nem engenhosa nem delirante, mediante o senhorio do entendimento, produz imagens de três espécies, de três estatutos diferentes; quais sejam elas: (i) imagens verdadeiras ou para a fantasia ou para o entendimento, representações de verdade apreendida pelos sentidos e assim reconhecidas; (ii) imagens verossímeis para a fantasia $e$ para o entendimento; (iii) imagens diretamente verdadeiras ou verossímeis para a fantasia, mas apenas indiretamente para o entendimento, visto seja falso o sentido direto, ou reto, da imagem. Nessa tripartição, as duas primeiras espécies, percebidas ou pendentes da apreensão sensível, são entendidas pelo tratadista como "símplices" e "naturais"; a terceira espécie é a que se diz "artificial fantástica".

Não é demasiado forçoso recordar que é fantástica, nos termos da doutrina platônica, uma das duas espécies de mimêsis, segundo o Estrangeiro dramatizado no Sofista (PLATÃO, Soph. 266 a ss.). Por um lado, nesse diálogo, é eikastikê (icástica) a mimese que opera em conformidade com as grandezas do 
exemplo, reproduzindo-lhe a simetria, respeitando-lhe as proporções (PLATÃO, Soph. 235 b-236 c; 266 d.) (SANTOS, 2002, p. 208-209). Para Francisco José Freire, subordinado à autoridade de Gian Vicenzo Gravina, trata-se de "imitaçaõ do particular" que "tem por objecto todas as acções, e cousas, que procedem da natureza, ou da Arte, e naõ menos da Historia, que da invençaõ de alguem" (FREIRE, 1759, t. I, p. 35-39). Por outro lado, é phantastikê (fantástica) a mimese que distorce as grandezas do exemplo, para que, distorcendo-as, pareça o artífice manter-lhe as proporções, tendo em vista a distância de apreensão pressuposta, e adequada, entre as obras assim produzidas e a recepção a que se destinam. Ademais, para Francisco José Freire, trata-se de "imitaçaõ do universal" que "tem por objecto tudo o que naõ existindo per si, tem novo ser, e vida, nascendo da fantasia do Poeta, quando entra a inventar novas cousas ou acções similhantes ás historias que se bem nao succederaõ, podiaõ succeder" (FREIRE, 1759, t. I, pp. 35-39).

Nesses mesmos termos, para Francisco José Freire, por um lado, a particularidade da mimese icástica faz pender a poesia para a história, cujo lugar privilegiado nas doutrinas poéticas setecentistas já se referiu. Entre os autores portugueses de gênero épico, no século XVIII, esse pendor, de acordo com os estudos de Ivan Teixeira, opera-se pragmaticamente como glosa, em verso, de cronistas da história lusa e pode-se exemplificá-lo com poemas como Conquista de Goa (1759), de Francisco de Pina de Sá e de Mello, Lisboa Reedificada (1780), de Miguel Maurício Ramalho, Uraguay (1769), de Basílio da Gama, ou Caramuru (1781), de Santa Rita Durão (TEIXEIRA, 1999, p. 249). Por outro lado, a universalidade da mimese fantástica supõe a imitação de matéria inexistente na natureza, mas inventada pela fantasia poética do artífice. Essa compreensão do Sofista é de traços duradouros, já é lida em Gregorio Comanini, no diálogo Il Figino, overo del fine della pittura, de 1591, em que a personagem Stefano Guazzo põe a distinção nos seguintes termos: a imitatione icastica "è quella, che imita le cose, le quali sono" ("é aquela que imita as coisas que são"), ao passo que a imitatione fantastica "è quella, che finge cose non essistenti" ("é aquela que finge as coisas não existentes"), à maneira da pintura de Giuseppe Arcimboldo (COMANINI, 1591, p. 28-30).

Ademais, são manejados na análise dessas espécies de imagem icástica e fantástica, como traços distintivos, o 
verdadeiro e o verossímil. São categorias que a doutrina poética de Ludovico Antônio Muratori e de Francisco José Freire, por conseguinte, reacomoda ao especificar o verdadeiro, isso significa "il vero della natura", o "verdadeiro da natureza", consoante distinção que supõe, por um lado, "quel vero che in fatti è, o pure, è stato" ("aquelle verdadeiro, que com effeito he, ou foy") e, por outro lado, "quel vero che verisimilmente è stato, o pur poteva, o doveva essere secondo le force della natura" ("o outro he o que verosimilmente foy, e tambem podia, ou devia ser, segundo as forças da natureza"). A doutrina esmiúça-o, compete a primeira espécie à teologia, à matemática, à história e às demais ciências, e decorre a ciência da cognição do "vero necessario, o evidente, o moralmente certo" ("verdadeiro necessario, ou evidente, ou moralmente certo"); a segunda, sobretudo, compete à poesia, e decorre a opinião da cognição do "vero possibile, probabile, $e$ credibile, che Verisimile poi comunemente vien detto" "verdadeiro possivel, provavel, e crivel, que vulgarmente se diz verosimil") (MURATORI, 1706, p. 94; FREIRE, 1759, t. I, p. 72).

A exposição que pende de Ludovico Antônio Muratori não é insignificante. No que se pode avançar, é lição aristotélica que entrelaça e relê, mesmo ao revés, as lições da Poética de Aristóteles relativas ao necessário, ao possível, ao provável, ao sucedido e ao crível (ARISTÓTELES, Poet. 9; 25), de modo que, de tal leitura, decorra a asserção da primazia da verdade e, por que não, tendo em vista o que interessa a Aristóteles nesse nono capítulo do tratado, e a despeito do que nele defende o filósofo, a primazia da história. O que, diga-se, não estranham os leitores da Poetica d'Aristotele uulgarizzata, de Ludovico Castelvetro (ca. 1505-1571), sabedores de que, "prima di natura fu la verità che la verisimilitudine, E prima di natura fu la cosa rappresentata [a história] che la cosa rappresentante [a poesia]" (ARISTÓTELES, 1570, p. 3).

Isso posto, talvez crentes, como Ludovico Castelvetro, nas luzes da história e da verdade, sem a qual "la poesia camina in oscurissime" (ARISTÓTELES, 1570, p. 4), Ludovico Antônio Muratori e Francisco José Freire ensinem quase que ipsis litteris:

che sempre un qualche vero serve di fondamento alle invenzioni, $e$ alle dicerie poetiche; $e$ che queste non possono esser belle, quando non ci fanno apprendere qualche verità o evidente, e certa, o pur possibile, e verisimile. [...] Mille pezzi di Storia, di Geografia, di Filosofia, d'altre Scienze, e Arti; mille descrizioni di luoghi, fiumi, animali, e altre cose verissime ci fa tutto giorno veder la Poesia; 
e la maggior parte de' sentimenti, ch'ella usa contiene la verità evidente, e reale. Il resto delle altre invenzioni, e descrizioni, de gli altri avvenimenti, e sentimenti, ch'ella ci fa vedere, e udire, e ch'ella industriosamente finge, contiene, o dee contenere il vero possibile, credibili, e probabile. Ove o il primo vero, o il secondo non si ravvisa dall' intelletto nella nobile, e seria Poesia, anzi in ciascuna parte della Poesia: egli può tenersi per certo, che non ne sentiremo diletto, $e$ che non ci apparirà bella, tuttoché il nuovo, e il maraviglioso in lei si ravvisi, troppo dispiacendoci il falso, l'impossibile, l'incredibile, o sia l'inverisimile. Il Poeta adunque nobile e serio sempre ci rappresenta cose veramente avvenute certe, ed esistenti; o pur ne finge colla sua fantasia di quelle, che veramente possono, o potevano, debbono, o dovevano essere, e accadere, generando nella mente nostra, o scienza, ovvero opinione. (MURATORI, 1706, p. 95-96)

que sempre algum verdadeiro serve de fundamento ás invenções poeticas, e que estas naõ podem ser bellas, quando naõ nos fazem aprehender alguma verdade, ou certa, ou também possivel, e verosimil.

[...] Todos os dias nos mostra a Poesia mil pedaços de Historia, de Geografia, de Filosofia, e outras Sciencias, e Artes; mil descripções de lugares, de rios, de animaes, e de outras cousas, saõ verdadeiras; antes pela mayor parte os conceitos de que ella usa, contém a verdade evidente, e real. O resto das outras invenções, e descripções dos outros successos, e conceitos, que ella nos faz ver, e ouvir, e que industriosamente finge, contém, ou deve conter o verdadeiro possivel, crivel, e provavel. Onde o entendimento naõ descobrir na seria, e nobre Poesia, e em qualquer de suas partes, ou o primeiro verdadeiro, ou o segundo; he certo, que a tal composição naõ causará deleite, nem parecerá bella, ainda que se encontre o novo, e o maravilhoso; porque nos ha de causar o falso hum grande desagrado, como cousa impossivel, incrivel, ou inverossimil. Por isso o Poeta, que he nobre, e serio, sempre nos representa as cousas verdadeiramente succedidas, certas, e existentes; ou tambem finge com a sua fantasia as que verdadeiramente pódem, ou podiaõ, devem, ou deviaõ ter, e succeder, causando deste modo, ou sciencia, ou opiniaõ em o nosso entendimento. (FREIRE, 1759, t. I, p. 72)

Ora, assentado nessas lições, cujos pressupostos em torno do verdadeiro e do verossímil serão pormenorizados, pode Francisco José Freire afirmar as "fantasias monstruosas", a "fantasia depravada", a "estragada imaginativa", das quais intelectualmente não decorrem nem "sciencia" nem "opiniaõ", a fim de, por consequência, assegurar, no discurso de censura, essa afecção viciosa que diz ser própria de poetas tragicômicos. À maneira dos furiosos, dos melancólicos, consoante a Arte 
poetica, ou regras da verdadeira poesia em geral, são eles impotentes ou obscurecidos de entendimento, governados por fantasia desmedida que nada apreende de verdadeiro, de quem resulta senão que espectros, equivalentes, nos termos do vitupério, à tragicomédia, a qual o tratado figura, desarrazoada, como contrafação de viciosa invenção, gênero sem proporção, sem ordem e sem unidade, resultante da conjunção de "cousas entre si discordes, inimigas, e incompativeis", ambicionando, contra artem, a virtude da unidade e a unidade da virtude, a despeito das diferenças que, segundo o preceito, fazem da tragédia e da comédia gêneros de poema forjados conforme códigos poeticamente antipáticos e opostos.

Ora, tragédia e comédia, ensina Francisco José Freire, são espécies de "Poesia Dramatica, ou representativa". Concordam, pois, ambas, consoante pressupostos aristotélicos, no modo como se constrói a imitação, pois o poeta "imita occultandose a si, e introduzindo pessoas a fallar". Ademais, devem ambos os gêneros "ter justa grandeza, verosimilhança, accidentes maravilhosos, enredo, unidade, tanto na acçaõ, como no tempo, e lugar, e a soluçaõ, que for necessaria, ou verosimil" (FREIRE, 1759, t. I, p. 2; 122). Todavia, prescritas como opostas e antipáticas, como "aves e serpentes", como "cordeirinhos e tigres", fazem-se incompatíveis tragédia e comédia. Entrecruzadas, pois, as categorias distintivas elencadas pelo preceptista, ou seja, "materia", "pessoas", "diç̧aõ", "affectos" e "fim", essas incompatibilidades de gênero podem sintetizar-se da seguinte maneira: a tragédia fabula "materia" amiúde deduzida da história, tratando "de acções horrorosas, e lastimosas" sucedidas a "pessoas" ilustres, afamadas, tais quais "Reys, Principes, e Personagens de grande qualidade, e dignidade, cujas decadencias, mortes, desgraças, e perigos" movam "affectos", ou seja, "excitem terror, e compaixaõ nos animos do auditorio, e os curem, e purguem destas, e outras paixões, servindo de exemplo a todos, mas especialmente aos Reys, e pessoas da mayor authoridade, e poder", segundo o "fim" próprio ao gênero; ao passo que a comédia plasma "materia" alheia à verdade, "fingida ao arbitrio" do poeta, ou seja, é "imitaçaõ de hum facto particular, $e$ de pouca importancia" sucedido a "pessoas" cujos nomes não são verdadeiros, de maneira que, em termos de "affectos", "mova o riso", "acabe com fim alegre, e se encaminhe a ser util, divertindo ao 
auditorio, e inspirando o amor á virtude, e aversaõ ao vicio", segundo o "fim" próprio ao gênero.

Enfim, na tragédia, nada de "glórias interinas", poderia afirmar o melancólico e desmemoriado narrador Bento Santiago, de Dom Casmurro. Na comédia, nada de reis, príncipes, imperadores ou "outras pessoas desta esféra", afirma o preceptista Francisco José Freire, embora não deixe de apontar que contra "esta regra peccaraõ quasi sempre os Hespanhoes". Enfim, nada de tragicomédia, figurada pelo tratadista português, já se sabe, como misto imperfeito e vicioso, porque, em suas palavras, dos opostos preceituados meio-termo não é possível. Essa impossibilidade, por ora, se sintetiza na afirmada carência de verossimilhança e de decoro subjacentes à encenação de gênero, também dramático, em que "pessoas Reaes, e plebeas tenhaõ hum mesmo caracter, e lugar", em que "caiba o estylo grave, e o humilde, e que a graciosidade de ditos, e factos, se una com a veneraçaõ das pessoas, e com a severidade dos costumes" (FREIRE, 1759, t. II, p. 152). Nada, enfim, de "vestir hum Rey com os vestidos de algum homem da plebe, para elle deste modo se aliviar do pezo da severidade Real", já que, segundo a Arte poetica, ou regras da verdadeira poesia em geral, assim fazer seria como "formar hum Poema da Bucolica, e da Eneida, e intitulallo Buccoleroico!" (FREIRE, 1759, t. II, p. 154).

Condizentes com as distinções de invenção, visto que delas dependentes, operam-se entre os gêneros confrontados, tragédia e comédia, distinções de elocução, de "diç̧aõ", como quer Francisco José Freire. Assim, "o estylo da Tragedia, como contém grandes personagens, e affectos violentos, deve ser sublime, e ornado de figuras rhetoricas, que saõ as que melhor explicaõ as paixões"; ao passo que o estilo da comédia, a ele, "só pertence huma locuçaõ commũa, natural, facil, e pura, porque as pessoas, que devem representar nella, haõ de ser ordinarias, ou de mediana condiçaõ, ás quaes só convém similhante estylo pois seria inverosimil, que em acções, e sujeitos humildes houvesse conceitos, e vozes improprias da sua esféra" (FREIRE, 1759, t. II, p. 13; 21; 114; 121).

Nos capítulos XXVIII e XXIX da Arte poetica, ou regras da verdadeira poesia em geral, insistentemente isso se nota, a asserção da oposição entre tragédia e comédia delimita preceitos antitéticos e estabelece desvios. Já se conhece, esses desvios afirmam-se da ordem do discurso tragicômico e têm 
como exemplum privilegiado Il Pastor Fido, que deve evidenciar a particularidade dos vícios do gênero. São desvios que enformam o monstrum:

[...] naõ he muito verosimil a diccaõ taõ culta, e as sentenças profundas; porque os que fallaõ sempre saõ pessoas do campo, ainda que naquella Corte rustica sejaõ principaes algumas dellas. (FREIRE, 1759, t. II, p. 161)

Para Francisco José Freire, muito embora essa "Corte rustica" seja alvo de concessão, ao fim, ela não autoriza a elocução culta. É, sobretudo, evidência de inadequação. São conhecidas as objeções de mesmo teor aos poemas em registro grave de D. Luís de Góngora. A censura, tal como posta, opera argumentos conformes às críticas do italiano Gian Vicenzo Gravina (1664-1718). De acordo com o tratado Della ragion poetica, estampado em Roma, em 1708 , seria tolerável a "novità d'invenzione" que enreda "nelle arti cittadine anche i genj pastorali", para que se teça a trama em cena, se nos poemas assim retoricamente inventados, ainda que se figurassem pastores e ninfas bastante esplêndidos e argutos, houvesse, sobretudo, "semplicità" (GRAVINA, 1708, p. 200). Para Gian Vicenzo Gravina, porém, como para Francisco José Freire, não é isso o que Il Pastor Fido encena:

[Giovanni Battista Guarini] trasportò nelle capanne anche le corti, applicando nel suo Pastor-fido a quei personaggi le passioni, e costumi delle anticamere, e le più artifiziose trame de i gabinetti: con ponere in bocca de i pastori precetti da regolare il mondo politico; e delle amorose ninfe pensieri sì ricercati, che pajono uscite dalle scuole de i presenti declamatori, ed epigrammisti. [...] Non niego però, che'l Guarini, avendo introdotta prole di semidei, ed imitato il costume di quelle età, nelle quali i pastori al governo pubblico, ed al sacerdozio ascendeano; non avea da conservar la semplicità, e meno la rozzezza de i pastori ignobili. (GRAVINA, 1708, p. 200-201)

[Giovanni Battista Guarini] transportou para as cabanas também as cortes, aplicando, em seu Pastor Fiel, a esses personagens [pastores e ninfas], as paixões e costumes das antecâmaras, e as mais artificiosas tramas dos gabinetes, ao pôr na boca dos pastores preceitos para regular o mundo político, e das amorosas ninfas pensamentos tão estudados, que parecem elas saídas das escolas dos atuais declamadores e epigramistas. [...] Não nego, todavia, que Guarini, havendo introduzido prole de semideuses e imitado o costume daquele tempo, no qual os pastores ao governo público e ao sacerdócio

2 Tradução nossa. ascenderam, não tinha de conservar a simplicidade e muito menos a rustiquez dos pastores ignóbeis. ${ }^{2}$ 
Gian Vicenzo Gravina, é verdade, não recusa abrandar a avaliação e, como se pode ler, sucede-lhe mesmo afirmar que o poeta não havia de conservar a simplicidade ou a rusticidade dos pastores; no entanto, a prática compositiva, essa "novità d'invenzione", segundo afirma, soa-lhe "affettata e puerile". As censuras de Francisco José Freire vez ou outra aparentam ser mais incisivas que as de Gian Vicenzo Gravina, embora, como se pôde e pode-se notar, sejam-lhes semelhantes as estratégias de argumentação. Ambos os preceptistas, o italiano e o português, intentam estabelecer protocolos de leitura de Il Pastor Fido, porém, ainda no século XVIII, a despeito da contenda, é essa obra afamada, e as críticas a ela são feitas como se fosse de bom tom não esquecê-lo nem desconsiderálo, para que àqueles que as fazem não se imputasse a pecha da necedade (GRAVINA, 1708, p. 201):

Naõ duvido, que por muitas circunstancias [a tragicomédia Il Pastor Fido] se fizesse merecedora deste applauso; porém igualmente tem outras, que devem ser censuradas no tribunal de huma critica sevéra. $O$ que geralmente tem arrebatado os animos, he o estylo desta Obra; e a mim me parece, que he a primeira cousa, que naõ deve ser louvada porque a frase deste Poeta nem he tragica, nem comica, nem tragicomica, mas toda lyrica; porque he toda cheya de brincos, e perfumes amorosos; tudo he mel, e assucar, tudo cores, e luzes, e tudo naõ artificios, mas huns esforços artificiaes, buscados de proposito, e collocados em lugares que nao saõ devîdos, e por isso contrarios, ou ao decoro da Obra, ou ao costume das pessoas, ou ao verosimil da imitaçaõ. Parecerá em nós talvez demasiado este juizo; porém lea esta Fabula o Leitor sabio, e desapaixonado, que certamente encontrará nella ser quasi tudo huma enfiada de Madrigaes amorosos, unidos successivamente huns aos outros. (FREIRE, 1759, t. II, p. 155-156)

Ojuízo de Francisco José Freire só corrobora o que já se leu, visto que amplifica a monstruosidade do poema, à luz de bases doutrinárias antes desenredadas. O acúmulo desproporcionado que delineia as incongruências de Il Pastor Fido, e torna o gênero tragicômica caricatura poética, ganha matéria lírica, como que plumas coloridas em corpo de cabeça humana e pescoço equino, se é conveniente fazer ecoar o prólogo da Epistula ad Pisones, de Horácio. Nos termos de Francisco José Freire, tudo são brincos, perfumes, cores, luzes, tudo são artifícios elocutivos de matiz lírica, por isso deslocados, que não somente concorrem 
para a monstruosidade imputada ao gênero, pois pendentes de invenção que opera temas amorosos, lidos na chave da extravagância e da variedade pródiga (SANTOS, 2002, p. 195), senão também que a dissimulam, ou assim intentam, em vista dos efeitos que o tratadista diz o "estylo desta Obra" suscitar ao arrebatar os ânimos da recepção.

O corpo tragicômico, assemelhado a "huma enfiada de Madrigaes amorosos", cuja sucessividade parece alheia a qualquer razão de disposição, faz-se assim, de acordo com esse juízo de censura, deleitável em sua doçura amorosa e, para que o engano não perpetue prática que iteradamente se diz viciosa, exige "Leitor sabio, e desapaixonado", o qual, numa sapiente apatia, ao poema de Giovanni Battista Guarini atribua a inadequação, e não ao juízo de vitupério que a Arte poetica, ou regras da verdadeira poesia em geral enuncia. Esse juízo, embora dito severo, mantém o tom de ponderação que insiste na impropriedade do estilo de Il Pastor Fido, na feição monstruosa do poema.

\section{REFERÊNCIAS}

AQUINO, Tomás de. Suma Teológica. Volume II: Parte I (Questões 44-119). São Paulo: Edições Loyola, 2002.

ARISTÓTELES. De anima. Livros I, II e III. $2^{\mathrm{a}}$ edição. Apresentação, tradução e notas de Maria Cecília Gomes dos Reis. São Paulo: Editora 34, 2012.

Poética. Tradução, introdução e notas de Paulo Pinheiro.

São Paulo: Editora 34, 2015.

Poetica d'ristotele uulgarizzata, et sposta per Ludovico Castelvetro. Stampata in Vienna d'Austria, per Gaspar Stainhofer, l'anno del Signore M.D. LXX [1570].

COMANINI, G. Il Figino overo del fine della pittura. Mantova: per Francesco Osanna, 1591.

FOUCAULT, M. Os anormais. Curso no Collège de France (19741975). Edição estabelecida sob a direção de Franços Ewald e Alessandro Fontana, por Valerio Marchetti e Antonella Salomoni. Tradução de Eduardo Brandão. São Paulo: Martins Fones, 2011. 
FREIRE, F. J. Arte Poetica, ou Regras da Verdadeira Poesia em geral, e de todas as suas especies principaes, tratadas com juizo critico: Composta por Franscisco Joseph Freire, Ulyssiponense. Segunda edição. ....Fungar vice cotis, acutum, Reddere qui ferrum valet, exfors ipsa fecandi: Munus, \& Officium nil scribens ipse, decebo, Unde parentur opes; quid alat, formetque poetam; Quid deceat, quid non; quo virtus quo ferat error. Horat. in Poetic. Lisboa, Na Offic. Patriarcal de Francisc[o]. Luiz Ameno, M.DCC.LIx. [1759] Com as licenças necessarias.

Diccionario poetico, para o uso dos que principiaõ a exercitarse na Poesia Portugueza: Obra igualmente util ao orador principiante. Seu author Candido Lusitano. floriferis ut apes in saltibus omnia libant, Omnia nos itidem depascimur aurea dicta, Aurea perpetua semper dignissima vita. Lucret. 3. Tomo I, Lisboa, Offic. Patriarcal de Francisco Luiz Ameno. MdccLXv. [1765] Com as licenças necessarias.

GUARINI, G. B. Il Pastor Fido. Tragicomedia Pastorale di Battista Gvarini. Dedicata al Ser. ${ }^{\mathrm{MO}}$ D. Carlo Emanvele. Dvca di Savoia \&c. Nelle Reali Nozze di S.A. con la ser.ma Infante D. Caterina d'Avstria. Con privilegi. In Venetia, Presso Gio, Battista Bonfadino [1590].

GRAVINA, G. V. Della ragion poetica libri due. In Roma, presso Francesco Gonzaga, MDCCVIII. [1708] Con Licenza de' Superiori.

HORÁCIO. Arte poetica de Q. Horacio Flacco traduzida, e illustrada em portuguez por Candido Lusitano. Lisboa: Na officina Patriarcal de Francisco Luiz Ameno, 1758.

MELLO, F. de P de S. de. Triumpho da Religiaõ. Poema EpicoPolemico; que à Santidade do Papa Benedicto XIV. Dedica Francisco de Pina e de Mello, Moço Fidalgo da Casa de Sua Majestade Fidelissmo, e Academico da Academia Real da Historia Portuguesa. Coimbra: Na Officina de Antonio Simoens Ferreira, impressor da Universidade, Anno de 1756. Com todas as licenças necessarias.

MUHANA, A. A epopéia em prosa seiscentista: uma definição de gênero. São Paulo: Editora da Unesp, 1997. 
MURATORI, L. Della perfetta poesia italiana spiegata, e dimostrata con varie osservazioni da Lodovico Antonio Muratori. Tomo primo. ... In Modena, M. DCCVI. [1706] Nella Stampa di Bartolomeo Soliani. Con Lic. de' Superiori.

PLATÃO. O sofista. Tradução de J. Maia Jr., H. Murachco e J. T. Santos. Lisboa: Fundação Calouste Gulbenkian, 2011.

QUINTILIEN. Institution oratoire. Texte établi et traduit par Jean Cousin. Paris: Les Belles Lettres, 1975-1980, 7 vols.

SANTOS, M. M. "O monstrum da Arte poética de Horácio". Letras Clássicas, São Paulo, 2002, v. 4, p. 191-265.

TEIXEIRA, I. Mecenato Pombalino e Poesia Neoclássica: Basílio da Gama e a Poética do Encômio. São Paulo: Edusp, 1999. 


\section{Abstract \\ Anatomy of the monster: Francisco José Freire's reproach to the tragicomic poem}

Francisco José Freire (1719-1773), known as Cândido Lusitano, in the treatise Arte poetica, ou Regras da Verdadeira Poesia em geral, e de todas as suas especies principaes, tratadas com juizo critico (ed. 1748; $2^{\text {nd }} \mathrm{ed}$. 1759), condemns tragicomedy as a hybrid and vicious genre, neither tragic nor comic, without proportion or unity, and Il Pastor Fido, a pastoral tragicomedy composed by Giovanni Battista Guarini (1538-1612), whose first edition was published in 1590, is rejected as a bad work of art. The blame of tragicomedy and of the famous Italian poem is based on the metaphor of the monstrum, presented in the initial steps (vv. 14-31) of the Epistula ad Pisones, the Horace's Poetics (1st century B.C.). This epistle gives Francisco José Freire the criteria for judging poetry in the Portuguese eighteenth-century.

Keywords: Horace, Francisco José Freire; Giovanni Battista Guarini; tragicomedy; monstrum. 